\title{
A job-exposure matrix for use in population based studies in England and Wales
}

\author{
B PANNETT, D COGGON, AND E D ACHESON
}

From the MRC Environmental Epidemiology Unit, University of Southampton, Southampton General Hospital, Southampton SO9 $4 X Y$, UK

ABSTRACT The job-exposure matrix described has been developed for use in population based studies of occupational morbidity and mortality in England and Wales. The job axis of the matrix is based on the Registrar General's 1966 classification of occupations and 1968 classification of industries, and comprises 669 job categories. The exposure axis is made up of 49 chemical, physical, and biological agents, most of which are known or suspected causes of occupational disease. In the body of the matrix associations between jobs and exposures are graded to four levels. The matrix has been applied to data from a case-control study of lung cancer in which occupational histories were elicited by means of a postal questionnaire. Estimates of exposure to five known or suspected carcinogens (asbestos, chromates, cutting oils, formaldehyde, and inhaled polycyclic aromatic hydrocarbons were compared with those obtained by detailed review of individual occupational histories. When the matrix was used exposures were attributed to jobs more frequently than on the basis of individual histories. Lung cancer was significantly more common among subjects classed by the matrix as having potential exposure to chromates, but neither method of assigning exposures produced statistically significant associations with asbestos or polycyclic aromatic hydrocarbons. Possible explanations for the failure to show a clear effect of these known carcinogens are discussed. The greater accuracy of exposures inferred directly from individual histories was reflected in steeper dose response curves for asbestos, chromates, and polycyclic aromatic hydrocarbons. The improvement over results obtained with the matrix, however, was not great. For occupational data of the type examined in this study, direct exposure estimates offer little advantage over those provided at lower cost by a matrix.

In the search for occupational causes of disease, job title is often used as an index of the potential hazards to which a worker might have been exposed. Mortality and morbidity are examined in relation to the occupational and industrial categories defined in standard classifications such as, for example, those published by the Office of Population Censuses and Surveys (OPCS). ${ }^{1-3} \mathrm{~A}$ drawback to this approach is the incomplete correspondence between the job categories studied and the exposures which they entail. The same exposure may occur in many different occupations and industries, whereas within a single job only a proportion of workers is exposed. Analyses might be improved if jobs were reclassified in a way that corresponded more closely with exposure to suspected hazards.

In recent years two techniques for grouping jobs

Received 11 March 1985

Accepted 1 April 1985 according to exposure have been described. In the first method jobs are coded to standard classifications of occupation and industry in the usual manner but in the analysis job categories that share an exposure of interest are aggregated. For example, in the OPCS 1971 decennial supplement on occupational mortality an attempt was made to group occupations involving exposure to dusts, gases, and fumes, and to examine their combined mortality. ${ }^{4}$ The method may be developed to allow simultaneous study of a wide range of potential hazards, and it is then helpful to record the relation between jobs and exposures in the form of a matrix or table with job categories listed along one axis and exposures along the other. ${ }^{5}$ Whether or not an exposure occurs in a job is indicated in the appropriate cell of the table. If in addition exposures can be graded then dose response relations may be examined.

Job-exposure matrices take into account the diversity of jobs in which an exposure may occur, but 
they do not distinguish differences in exposure within job categories. If the categories on the job axis of the matrix are not sufficiently specific then useful information may be lost when jobs are coded. The second method of grouping jobs by exposure overcomes this weakness. Each occupational history is reviewed by a trained expert who assigns exposures on an individual basis without any intervening coding process. ${ }^{6}$ He thus makes use of all available information including factors such as the time and place at which jobs were held. Exposures estimated in this way will in general be more accurate than those inferred from job-exposure matrices but the method requires more time and expertise, and is therefore more expensive.

It is important to establish the relative merits of these two approaches in practice. We describe here a job-exposure matrix which we have developed for use in population based studies in England and Wales. The matrix has been applied to data from a case-control study of lung cancer, and the results in respect of five known or suspected carcinogens are compared with those obtained when exposures were estimated directly from the original histories.

\section{Method}

\section{JOB-EXPOSURE MATRIX}

The job axis of the matrix is based on the Registrar General's 1966 classification of occupations ${ }^{1}$ and 1968 classification of industries. ${ }^{3}$ The 1966 classification of occupations is made up of 211 occupational units, each described by a three digit code, while the 1968 classification of industries uses a four digit code to describe 355 industrial units and subunits. It follows that any job may be described by a seven digit code (three digits for occupation and four for the industry in which the occupation was carried out), and that in theory $211 \times 355=74905$ such combinations of occupation and industry are possible. In practice many combinations of occupation and industry are implausible-for example, there are no fishermen in the coalmining industry. Nevertheless, a large number of pairings do occur, and to facilitate construction of the matrix, we have aggregated combinations of occupation and
Table 2 Agents included on the exposure axis of the matrix

Acrylonitrile

Adhesives: natural

Adhesives: synthetic

Antiknock agents

Aromatic amines

Arsenic and arsenic compounds

Asbestos

Benzene

Beryllium and beryllium compounds

Cadmium and cadmium compounds

Carbon tetrachloride

Chlorophenols

Chromates

Cold

Contact with animals

Electromagnetic fields

Contact with public

Cutting oils

Degreasing agents

Detergents

Diesel fumes

Dyestuffs

Coal dust

Other inorganic dust

Cereal dust

Textile dust

Wood dust

Other organic dust

Epoxy resins

Ethylene oxide

Formaldehyde

Heat

Polycyclic aromatic hydrocarbons (inhaled)

Polycyclic aromatic hydrocarbons (skin contact)

Herbicides

Ionising radiation

Lead and lead compounds

Mercury and mercury compounds

Nitrates

Organic solvents

Outdoor occupation

Paints

Polychlorinated biphenyls

Printing inks

Solder fumes

Styrene

Artificial ultraviolet light

Waxes and polishes

Welding fumes

industry that have a similar profile of exposure to form "job groups" (table 1). The 669 job groups so defined constitute the job axis of the matrix. The design is such that once a job has been coded to the appropriate Registrar General's classifications it is uniquely assigned to a job group. Unlikely or impossible combinations of occupation and industry are included in categories of the type "specified

Table 1 Some examples of "job groups"

\begin{tabular}{llll}
\hline Industrial units* & & Occupational units $\dagger$ \\
\hline 101 & Coalmining & Electrical and electronic workers \\
261 & Coke ovens and manufactured fuel & $027-033$ & Welders, gas cutters, braziers \\
$001-906$ & All industries & $139-141$ & Clerical workers \\
$471 \cdot 1$ & Saw-milling & 211 & Inadequately described
\end{tabular}

*As defined in the Registrar General's 1968 classification of industries. ${ }^{3}$

†As defined in the Registrar General's 1966 classification of occupations. ${ }^{1}$ 
Table 3 Grades of exposure distinguished in the matrix

\begin{tabular}{ll}
\hline High & $\begin{array}{l}\text { A high proportion of workers heavily } \\
\text { exposed } \\
\text { A small proportion of workers heavily } \\
\text { exposed or a high proportion of } \\
\text { workers lightly exposed } \\
\text { M small proportion of workers lightly } \\
\text { exposed } \\
\text { Exposures trivial or do not occur }\end{array}$ \\
\hline
\end{tabular}

occupation, industry not elsewhere classified." Job groups of the form "specified occupation, industry inadequately described" and "specified industry, occupation inadequately described" allow application of the matrix to incomplete data.

The exposure axis of the matrix comprises the 49 agents listed in table 2 . The choice of these exposures was influenced in part by suspicions that they cause occupational disease-some for example, are suspected of causing cancer. In addition, exposures were more likely to be selected if they occur in a variety of occupations and industries, since it is under these circumstances that a job-exposure matrix is most likely to improve on conventional methods of analysis. Several of the agents listed in table 2 are known industrial carcinogens. These were included because of the possibility that they might confound associations 'with other occupational exposures, and also so that the sensitivity of the matrix method could be evaluated.

We expect that the matrix will be used mainly for analysing retrospective data, and so in relating exposures to jobs we have looked at industrial practices over the past 40 years. Where the nature of a job has changed during this time-for example, through the introduction of new technology or the control of hazardous substances-we have tried to derive an "average" exposure for the period. Within the matrix we have distinguished four grades of exposure-" "high," "moderate," "low," and "none." The definition of these categories depends on both the proportion of workers within a job group who are likely to have been exposed and also the likely extent - that is, level and duration - of such exposure when it has occurred (table 3). Our assessment of the exposures associated with jobs is based on information obtained from other job-exposure matrices; from textbooks of industrial hygiene, occupational medicine, toxicology, and chemistry; from published papers; and by direct inquiry of trade federations and colleagues in industry. Where possible we have verified reported exposures from independent sources. Occasionally we have failed to find evidence that a job entails a particular exposure, but because our data are sparse we feel unable to exclude the possibility. In the matrix these exposures are classified as "unknown."
CASE-CONTROL STUDY

We have tested the matrix using data from a survey of cancer and occupation in young and middle aged men. A preliminary report of this survey has already been published, ${ }^{7}$ and a more detailed description is in preparation, so we here give only a brief account of the method by which data were collected. The study population comprised men aged 18-54 and resident in an area roughly equivalent to the counties of Cleveland, Humberside, and Cheshire together with the Wirral district of Merseyside. New cases of cancer diagnosed in the study population during the years 1975-80 were identified retrospectively from the records of hospital pathology departments and from cancer registration files. The occupational and smoking histories of these patients were then sought by means of a postal questionnaire addressed either to the patient himself, or if he had died to his next of kin. The overall response rate was $52 \cdot 1 \%$.

Histories were obtained for 312 patients with carcinoma of the bronchus and 1221 patients with other types of cancer. For each case of bronchial carcinoma a control was selected from the group of patients with other cancers. Controls were matched to cases for county of residence (for this purpose the Wirral was included with Cheshire), the source of the history (patient or relative), smoking (current smoker, ex-smoker, or non-smoker), and as closely as possible for age.

Between them, the 624 cases and controls were reported to have held 2985 jobs before diagnosis of their tumours. The job-exposure matrix was used to grade each of these jobs for exposure to three known lung carcinogens (asbestos, chromates, and inhaled polycyclic aromatic hydrocarbons, and two suspected carcinogens (formaldehyde and cutting oils). Two of us (DC, BP) then together reviewed the original occupational histories (blind to the case-control status of the subjects) and made revised estimates of exposure in the light of the full, reported job descriptions. Exposures estimated by this direct approach were compared with those inferred from the matrix.

Associations between exposures and carcinoma of the bronchus were examined by the method of

\section{Table 4 Diagnoses of controls}

\begin{tabular}{lc}
\hline Diagnosis & No of controls \\
\hline Carcinoma of bladder or renal pelvis & 38 \\
Carcinoma of stomach & 34 \\
Carcinoma of rectum & 33 \\
Carcinoma of colon & 28 \\
Lymphoma or leukaemia & 28 \\
Carcinoma of renal parenchyma & 20 \\
Other & 131 \\
Total & 312 \\
\hline
\end{tabular}


Table 5 Classification of jobs by exposure: number of jobs assigned to each grade of exposure by the matrix and by direct review of individual occupational histories

\begin{tabular}{|c|c|c|c|c|c|c|}
\hline \multirow[t]{2}{*}{ Agent } & \multirow[t]{2}{*}{$\begin{array}{l}\text { Grade of exposure assigned } \\
\text { by matrix }\end{array}$} & \multicolumn{5}{|c|}{$\begin{array}{l}\text { Grade of exposure assigned by direct review of original } \\
\text { occupational history }\end{array}$} \\
\hline & & None & Low & Moderate & High & Total \\
\hline Asbestos & $\begin{array}{l}\text { None } \\
\text { Low } \\
\text { Moderate } \\
\text { High } \\
\text { Total }\end{array}$ & $\begin{array}{r}2082 \\
504 \\
126 \\
2 \\
2714\end{array}$ & $\begin{array}{r}18 \\
116 \\
49 \\
0 \\
183\end{array}$ & $\begin{array}{r}3 \\
23 \\
33 \\
1 \\
60\end{array}$ & $\begin{array}{r}0 \\
1 \\
20 \\
7 \\
28\end{array}$ & $\begin{array}{r}2103 \\
644 \\
228 \\
10 \\
2985\end{array}$ \\
\hline Chromates & $\begin{array}{l}\text { None } \\
\text { Low } \\
\text { Moderate } \\
\text { High } \\
\text { Total }\end{array}$ & $\begin{array}{r}2362 \\
377 \\
116 \\
0 \\
2855\end{array}$ & $\begin{array}{r}3 \\
32 \\
55 \\
0 \\
90\end{array}$ & $\begin{array}{r}0 \\
21 \\
16 \\
2 \\
39\end{array}$ & $\begin{array}{l}0 \\
0 \\
1 \\
0 \\
1\end{array}$ & $\begin{array}{r}2365 \\
430 \\
188 \\
2 \\
2985\end{array}$ \\
\hline Cutting oils & $\begin{array}{l}\text { None } \\
\text { Low } \\
\text { Moderate } \\
\text { High } \\
\text { Total }\end{array}$ & $\begin{array}{r}2746 \\
153 \\
22 \\
5 \\
2926\end{array}$ & $\begin{array}{l}1 \\
4 \\
1 \\
12 \\
18\end{array}$ & $\begin{array}{r}5 \\
8 \\
5 \\
7 \\
25\end{array}$ & $\begin{array}{r}0 \\
7 \\
0 \\
9 \\
16\end{array}$ & $\begin{array}{r}2752 \\
172 \\
28 \\
33 \\
2985\end{array}$ \\
\hline Formaldehyde & $\begin{array}{l}\text { None } \\
\text { Low } \\
\text { Moderate } \\
\text { High } \\
\text { Total }\end{array}$ & $\begin{array}{r}2676 \\
111 \\
87 \\
0 \\
2874\end{array}$ & $\begin{array}{r}6 \\
69 \\
14 \\
0 \\
89\end{array}$ & $\begin{array}{r}1 \\
0 \\
21 \\
0 \\
22\end{array}$ & $\begin{array}{l}0 \\
0 \\
0 \\
0 \\
0\end{array}$ & $\begin{array}{r}2683 \\
180 \\
122 \\
0 \\
2985\end{array}$ \\
\hline $\begin{array}{l}\text { Inhaled polycyclic } \\
\text { aromatic } \\
\text { hydrocarbons }\end{array}$ & $\begin{array}{l}\text { None } \\
\text { Low } \\
\text { Moderate } \\
\text { High } \\
\text { Total }\end{array}$ & $\begin{array}{r}2473 \\
231 \\
11 \\
12 \\
2727\end{array}$ & $\begin{array}{r}36 \\
63 \\
45 \\
39 \\
183\end{array}$ & $\begin{array}{r}14 \\
21 \\
1 \\
26 \\
62\end{array}$ & $\begin{array}{r}3 \\
3 \\
0 \\
7 \\
13\end{array}$ & $\begin{array}{r}2526 \\
318 \\
57 \\
84 \\
2985\end{array}$ \\
\hline
\end{tabular}

conditional logistic regression for matched pairs, ${ }^{8}$ and the results obtained with the two techniques for estimating exposure were compared.

\section{Results}

Table 4 shows the main diagnostic categories that

Table 6 Associations with lung cancer in case-control study: relative risks* with 95\% confidence intervals and (in italics) the number of cases classified to the relevant exposure category

\begin{tabular}{|c|c|c|c|c|c|}
\hline Agent & $\begin{array}{l}\text { Method by which exposures were } \\
\text { assigned }\end{array}$ & Any exposure $†$ & Low exposure & Moderate exposure & High exposure \\
\hline \multirow[t]{2}{*}{ Asbestos } & Matrix & $0.99(0.73-1.34) 193$ & $0.87(0.61-1 \cdot 23) 108$ & $1 \cdot 18(0.78-1 \cdot 78) 80$ & $1.64(0.39-6.92) 5$ \\
\hline & From individual histories & $0.95(0.66-1.37) 82$ & $0.82(0.53-1.27) 46$ & $0.99(0.53-1.86) 23$ & $1.76(0.69-4.44) 13$ \\
\hline \multirow[t]{2}{*}{ Chromates } & Matrix & $1.39(1.02-1.91) 170$ & $1.30(0.90-1.88) 97$ & $1.55(1.01-2.39) 72$ & $1 \cdot 14(0.07-18.49) l$ \\
\hline & From individual histories & $1.49(0.95-2.31) 54$ & $1.38(0.82-2.32) 37$ & $1.64(0.74-3.62) 16$ & $\begin{array}{l}\text { One exposed case } \\
\text { No exposed controls }\end{array}$ \\
\hline \multirow[t]{2}{*}{ Cutting oils } & Matrix & $0.75(0.51-1.09) 63$ & $0.65(0.41-1.03) 35$ & $1.33(0.59-3.00) 16$ & $0.74(0.34-1.63) 12$ \\
\hline & From individual histories & $0.94(0.49-1.83) 18$ & $2.05(0.62-6.84) 8$ & $1.35(0.50-3.64) 9$ & $0.14(0.02-1.02) I$ \\
\hline \multirow[t]{2}{*}{ Formaldehyde } & Matrix & $1.05(0.84-1.75) 100$ & $1.01(0.64-1.60) 49$ & $1.47(0.91-2.37) 51$ & -0 \\
\hline & From individual histories & $1.18(0.71-1.95) 39$ & $1.27(0.74-2 \cdot 18) 32$ & $0.84(0.31-2.28) 7$ & -0 \\
\hline \multirow[t]{2}{*}{ Inhaled PAHs } & Matrix & $1 \cdot 13(0.82-1 \cdot 58) 135$ & $1.24(0.85-1.81) 89$ & $0.92(0.45-1.91) 17$ & $1.02(0.60-1.73) 29$ \\
\hline & From individual histories & $0.85(0.59-1.21) 81$ & $0.70(0.45-1.09) 51$ & $1.00(0.53-1.89) 21$ & $2.75(0.74-10.24) 9$ \\
\hline \multicolumn{6}{|c|}{$\begin{array}{l}\text { *Risks relative to subjects classed as having no exposure. } \\
\text { +Low, moderate, or high. } \\
\text { PAHs = Polycyclic aromatic hydrocarbons. }\end{array}$} \\
\hline
\end{tabular}


made up the control group. Tumours of the gastrointestinal tract and urinary system were the most common, but no single diagnosis accounted for more than $13 \%$ of controls. Eighty five per cent of case-control pairs were matched to within one year of age, and for no pair was the age difference greater than four years.

Table 5 shows how the two methods of estimating exposures compared when they were applied to the 2985 jobs reported in the study. In general, exposures were assigned less frequently on the basis of individual histories than when the matrix was used. An example of this trend is provided by process workers in the manufacture of inorganic chemicals. In the matrix inorganic chemical process workers were considered to have moderate exposure to chromates (a small proportion of workers heavily exposed). Within the study sample the job was reported ten times, but in nine instances the full history suggested that exposure to chromates was extremely unlikely. One subject had worked as an operative in the production of chromates and his exposure was upgraded to high. Discrepancies between the two methods were particularly common for certain job categories. For example the job group "construction workers not elsewhere classified" (based on a single occupational unit and single industrial unit in the Registrar General's classifications) included laggers with potentially high exposure to asbestos, tar layers with probable exposure to PAHs, and other workers who were unlikely to have been exposed to either of these agents.

When looking at associations between exposures and carcinoma of the bronchus, we classified subjects according to the highest grade of exposure assigned to any of their jobs. For example, the asbestos exposure of a man who had worked in three jobs, two with low exposure to asbestos and one with moderate exposure, was classed as moderate. Table 6 gives risk estimates calculated by grade of exposure for each of the five substances examined. Tighter $95 \%$ confidence intervals were obtained with the matrix than when exposures were estimated directly from the original histories. This reflects the larger number of jobs that were assigned exposure by the matrix. On the other hand, the risk estimates calculated for the three known lung carcinogens tended, at least in the higher exposure categories, to be greater when exposures were inferred directly. Only two of the associations were statistically significant at a 5\% level (any and moderate exposure to chromates as estimated by the matrix method).

\section{Discussion}

The idea of classifying jobs according to the exposures that they entail has attractions but certain practical difficulties must be overcome if the exercise is to be worth while. One problem is the selection of exposures for study. Most of the agents on the exposure axis of our matrix are known or suspected causes of occupational disease, but in retrospect our choice could probably have been better. In particular, one or two of the exposures (acrylonitrile, for example) occur in so few jobs that their effects are as likely to be apparent in conventional analyses of occupational mortality and morbidity as when a job-exposure matrix is used. In many instances we have chosen to examine mixed or grouped exposures (diesel fumes, herbicides) rather than single chemical compounds. This is because the more specific exposures that make up such categories are intercorrelated and cannot be reliably distinguished on the basis of job title. The biological effects of some agents depend on the route by which exposure occurs, and in the investigation of a suspected hazard it may be important to differentiate between jobs according to the type of exposure which they involve. Thus in our matrix we have distinguished between dermal and inhalational contact with PAHs.

Another difficulty is the grading of exposures. How should intermittent exposure to high concentrations of a substance be weighed against continuous low level exposure? How much emphasis should be placed on the proportion of workers in a job who are exposed as opposed to the extent of such exposure when it occurs? There are no simple answers to these questions. The aim is to demonstrate a clear association with disease incidence if a hazard is present and also a dose response effect, but dose response curves cannot be predicted in advance. The cut off points between exposure grades are therefore somewhat arbitrary, and effort must be concentrated more on ensuring internal consistency-for example, checking that welders in different branches of the chemical industry are graded similarly for exposure to artificial ultraviolet light. The maintenance of internal consistency is particularly a problem when exposures are inferred directly from individual histories, and it may help if, as in our study, a job-exposure matrix is used as a starting point for direct exposure estimates. For some agents we have chosen to ignore trivial exposures-for example, exposure to formaldehyde in side stream cigarette smoke-since otherwise virtually all subjects would be classed as potentially exposed.

A third problem is the validation of exposure estimates. Where possible we have confirmed the existence of occupational exposures from at least two independent sources, but almost certainly there are inaccuracies and inconsistencies in our grading of exposures. We intend to update the matrix in the 
future if and when such errors become apparent.

The difficulties which have been discussed so far apply to both methods of relating job title to exposure, but the design of job-exposure matrices poses additional problems. The definition of categories on the job axis of a matrix will determine how much information is lost when jobs are coded. If the classification of jobs is made too specific, however, it will become so long as to be unmanageable. A compromise is therefore necessary. Subsequent empirical evaluation may suggest categories (such as construction workers in our matrix) which could usefully be subdivided. Because job categories cannot be completely specific, assessment of the exposures which they entail must take into account the distribution of occupation and industry within the population to which the matrix is to be applied. In constructing our matrix we had to gauge what proportion of construction workers in England and Wales during the postwar period would have been laggers. Judgments of this type lie within the expertise of the occupational epidemiologist, and we believe that the grading of exposures in matrices is best carried out by occupational hygienists and epidemiologists working in collaboration.

A further option in the creation of job-exposure matrices is the addition of a time axis so that allowance may be made for historical changes in the exposures associated with jobs. ${ }^{9}$ Again, the increased accuracy of exposure estimates must be balanced against the extra time and expense entailed. In our matrix we have not distinguished patterns of exposure during different time periods.

When we applied our matrix to data from cases of lung cancer and controls we found that the tumour was significantly more common in subjects with possible exposure to chromates, but we were unable to show any overall association with asbestos or inhaled PAHs. There are several possible explanations for our failure to detect an effect of these known carcinogens. In the population under study the proportion of lung tumours attributable to asbestos and PAHs may only have been small. The investigation was restricted to men under the age of 55, but occupational carcinogens with long induction periods will produce more disease in the older age groups. (We did not allow for latency in our analysis because our information about dates of employment was incomplete.) Alternatively, we may have missed a carcinogenic effect because the occupational histories on which the study was based were inaccurate or lacked sufficient detail. A third possibility is that too much information was lost when jobs were coded before application of the matrix. This last explanation, however, seems unlikely since the risk estimates obtained when exposures were inferred directly from individual his- tories were even lower.

The carcinogenic effects of asbestos were apparent in the high exposure category, but the number of subjects classed as having high exposure to asbestos was small and the association was not statistically significant. Even in the high exposure grade not all subjects will necessarily have had contact with asbestos, and this may explain why their relative risk is less than those which have been found in cohort studies of asbestos workers.

As expected, the direct method of estimating exposures gave steeper dose-response curves than the matrix for the known carcinogens. The most striking divergence in risk estimates was for high exposure to PAHs (1.02 with matrix, 2.75 by direct method). Otherwise, the differences were small, and it would appear that for data of the type that were obtained in our case-control study direct exposure estimates offer little advantage over those provided by a matrix. Macaluso and his colleagues ${ }^{10}$ have carried out a similar comparison using occupational histories elicited at interview and, as in our study, the superiority of direct exposure estimates was more pronounced for PAHs than asbestos. The benefits of the direct approach are likely to be most obvious when detailed occupational histories are available since there is then scope for greater loss of information when jobs are coded.

Neither method of inferring exposure from job title suggested an association between lung cancer and formaldehyde or cutting oils. Nevertheless, a priori suspicions that these agents cause lung cancer were weak. In particular, a large cohort study has failed to show a clear excess of lung cancer among workers heavily exposed to formaldehyde. ${ }^{11}$

The value of job-exposure matrices in the search for occupational causes of disease has yet to be established. Their worth will only be proved if and when their use leads to the identification of new hazards. We intend to apply our matrix to further sets of data, and will follow up the more promising clues that are generated. In addition, copies of the matrix are available on magnetic tape for other investigators who wish to use it.

We thank Dr C Osmond and Mr P Winter for their help with the statistical analysis and computing; Dr D Edwards and Mrs S Gravestock for their help with the data collection; and the many colleagues whose advice we have sought in constructing the matrix.

\section{References}

${ }^{1}$ General Register Office. Classification of occupations (1966). London: HMSO, 1966. 
${ }^{2}$ Office of Population Censuses and Surveys. Classification of occupations, 1970. London: HMSO, 1970.

${ }^{3}$ Central Statistical Office. Standard industrial classification. London: HMSO, 1968.

${ }^{4}$ Office of Population Censuses and Surveys. Occupational mortality 1970-72. Decennial supplement for England and Wales. London: HMSO, 1978. (Series DS No 1.)

${ }^{5}$ Hoar SK, Morrison AS, Cole P, Silverman DT. An occupation and exposure linkage system for the study of occupational carcinogenesis. J Occup Med 1980;22:722-6.

${ }^{6}$ Siemiatycki J, Day NE, Fabry J, Cooper JA. Discovering carcinogens in the occupational environment: a novel epidemiologic approach. JNCI 1981;66:217-25.

${ }^{7}$ Coggon D, Pannett B, Acheson ED. Screening for new occupational hazards of cancer in young persons. Ann Occup Hyg 1984;28:145-50.

${ }^{8}$ Breslow NE, Day NE. Statistical methods in cancer research. Vol 1: The analysis of case-control studies. Lyon: International Agency for Research on Cancer, 1980.

${ }^{9}$ Acheson ED, ed. Job exposure matrices. Southampton: MRC Environmental Epidemiology Unit, 1983

${ }^{10}$ Macaluso M, Vineis $P$, Continenza D, Ferrario F, Pisani P, Andisio R. Job-exposure matrices: experience in Italy. In: Acheson ED, ed. Job exposure matrices. Southampton: MRC Environmental Epidemiology Unit, 1983.

${ }^{11}$ Acheson ED, Barnes HR, Gardner MJ, Osmond C, Pannett B, Taylor CP. Formaldehyde process workers and lung cancer. Lancet 1984;i:1066-7. 